\title{
Repetição: Movimento e transformações
}

Renata Cristina Alves * e Martha de Mello Ribeiro* *

RESUMO: No presente artigo trataremos algumas questões sobre repetição nos processos artísticos de Pina Bausch, dialogando as criações dessa encenadora com a teoria de Deleuze. Acreditamos que repetição não está ligada à reprodução do mesmo e do semelhante, mas à produção de singularidades e do diferente. Repetição é uma ação, repetir não é acrescentar uma segunda ou terceira vez à primeira, mas sim elevar a primeira a potências maiores. Esse conceito dialoga com os processos criativos da encenadora, a qual utiliza a repetição no intuito de obter essa elevação da potência das ações trabalhadas. Buscamos fazer uma pequena descrição de processos e possíveis ideais de Bausch ao utilizar a repetição em suas obras.

PALAVRAS-CHAVES: Repetição, Pina Bausch, processo de criação.

ABSTRACT: In this article we treat the repeat some questions about the artistic processes of Pina Bausch, dialoguing creations of that director with Deleuze's theory. We believe that repetition is not linked to the reproduction of the same and similar, but the production of singularities and different. Repetition is an action, repeat is not to add a second or third time at first, but the first raise the major powers. This concept speaks to the creative processes of director, which use repetition in order to obtain this increase in power of the responsive actions. We seek to make a short description of processes and possible ideals of Bausch using repetition in his work. KEY WORDS: Repetition, Pina Bausch, creation process.

\footnotetext{
*Professora Substituta da Universidade Federal de Sergipe, mestra em Estudos Contemporâneos das Artes pela Universidade Federal Fluminense, licenciada e bacharel em Dança pela Universidade Federal de Viçosa e Universidade Técnica de Lisboa (PT).

** Orientadora - UFF.
} 


\section{Introdução}

A repetição em dança sempre foi vista como uma forma de aprimorar uma técnica, um caminho para chegar à perfeição. Bausch vai além disso ao transformar a repetição num conceito estético de suas obras. Segundo Ciane Fernandes (2007), a encenadora usa a repetição para fragmentar as expressões de seus bailarinos e criar as narrativas em frases de movimento; assim, além de um conceito estético, utiliza a repetição como um instrumento criativo, através do qual seus dançarinos reconstroem suas histórias.

A repetição em seus processos criativos é utilizada para separar os gestos de seus significados e formas originais. Repete-se o gesto até ganhar um significado social e estético crítico, os cotidianos são repetidos até se tornarem abstratos e desconexos de suas funções diárias. A repetição obsessiva retira o gesto da sua espontaneidade cotidiana, tem como função desconstruir o movimento proposto pelo bailarino numa determinada unidade de tempo. $\mathrm{O}$ movimento ganha novas formas, significados e a repetição torna-se assim uma estética. A repetição dos movimentos torna o corpo consciente do seu papel simbólico e social em constante transformação.

As coreografias de Pina Bausch mesclam gestos cotidianos e movimentos técnicos. Em vários momentos, os gestos cotidianos, através da incessante repetição, ganham novos significados ou abstrações; não necessariamente relacionados às funções diárias para as quais servem. Isso ocorre não apenas em relação aos gestos utilizados, mas também às palavras eventualmente pronunciadas pelos bailarinos em algumas obras de Bausch. (TRAVI, 2011, p.27)

Segundo ainda a autora acima citada, Bausch utiliza a repetição como algo que leva à criação, à transformação e não uma simples reprodução mecânica.

\footnotetext{
A repetição dos gestos é um caminho para a transformação da forma, para a criação de novas e inesperadas sintaxes e para a invenção de novas estéticas. Mas Pina vai além. A coreógrafa faz uso da repetição também como método de inverter os efeitos convencionais atribuídos à mesma. Ou seja: Bausch critica a ideia de que qualquer processo de aprendizagem social formal implique a necessidade de uma disciplina baseada na repetição. (TRAVI, 2011, p.28)
}

Fernandes (2007) afirma que um gesto que se repete por várias vezes passa de uma simples expressão espontânea para um movimento estético. Quando um movimento é repetido exaustivamente, seu significado sofre mutações e provoca sentimentos e experiências nos bailarinos e na plateia. 


\section{Uma estética da Repetição}

A repetição é um elemento recorrente nas obras de Bausch, tanto nos elementos por ela utilizado em seus cenários como nas movimentações de seus bailarinos. A encenadora conseguiu trabalhar a repetição além do seu conceito, fazendo com que tudo que se repetisse nas suas cenas não fosse mera representação do primeiro signo.

Segundo Fernandes (2007), Bausch recorre à repetição para provocar o inesperado ou até mesmo o oposto da proposta trazida pelo bailarino; quer causar pela repetição um método coreográfico de transformação do gesto.

Em suas obras percebe-se a repetição no processo de criação (no qual ela pede que seus bailarinos respondam as suas perguntas e repitam as palavras ou os movimentos diversas vezes, até se tonarem orgânicos), na sua forma estética (nas suas obras a repetição de movimentos é uma das suas características mais marcantes), nos recursos cênicos (seus cenários são feitos pela multiplicação do mesmo objeto, por objetos, as cadeiras em Café Müller, as flores em Cravos), e na escolha dos temas abordados (por utilizar temas da vida, muitas das suas perguntas repetiam os temas mais comuns na vida como amor, ódio, solidão). Ou seja, a repetição é um dos seus maiores instrumentos criativos.

"Café Müller" é a obra de Bausch que talvez melhor represente o conceito de repetição defendido neste artigo. Nessa peça, além da repetição das cadeiras e mesas que ocupam todo o espaço cênico, sendo mais do que simples cenário, existe grande repetição de movimentos. Bausch não só repete um único movimento, como também repete uma frase, enfatizando ainda mais a ideia do desejo, da vida, do hábito.

O espetáculo é marcado por várias caminhadas, gestos, manipulações que se repetem várias vezes entre as cadeiras. Numa das cenas, uma bailarina se encontra com um bailarino, o abraça e os dois se mantêm nessa forma. Um terceiro bailarino desmancha esse abraço, movendo as partes dos corpos dos dois performers, provoca um beijo e a coloca nos braços do bailarino. Assim que ele a solta ela cai no chão e volta ao abraço inicial. Essas ações se repetem várias vezes até o momento em que o terceiro bailarino sai de cena e a bailarina repete toda a movimentação sozinha, como se ainda estivesse sendo manipulada pelo terceiro corpo ${ }^{1}$. A repetição aqui se dá no primeiro momento para a formação do hábito, a bailarina é manipulada até começar a fazer a ação sozinha. O início da frase de movimento se dá no abraço, o desejo 
dela de estar ali e sempre ser interrompida por alguém se torna um hábito, até que ela mesma desfaz e refaz a ação repetindo a frase inúmeras vezes. Quando o terceiro bailarino sai de cena, ela repete incessantemente e mais veloz a queda e volta ao abraço, até chegar à exaustão, ao cansaço, à fadiga da repetição e encontrar seu descanso na primeira forma, o abraço.

Bausch utilizava a repetição para criar novas perspectivas sobre um mesmo movimento. Kantor explica que a repetição não é fazer o movimento novamente e sim elevá-lo a uma potência maior, é uma forma de fazer novamente algo que já existe em algum lugar dentro de si. Para unir os pensamentos de Kantor e Bausch, iremos nos apoiar no conceito de repetição deleuziano (2000), de que a repetição nada muda no objeto que se repete, mas muda algo no espírito que a contempla.

O filósofo traz novas reflexões sobre o conceito de repetição; para ele, não se trata de generalidade, ou seja, não é uma união de coisas supostamente semelhantes no mesmo conceito sob a mesma lei; repetir não é fazer tudo igual. Segundo Deleuze (2000), numa generalização um termo pode ser trocado por outro, na repetição isso não acontece, pois ela não está ligada à reprodução do mesmo, mas à produção de singularidades e diferenças.

A generalidade apresenta duas grandes ordens: a ordem qualitativa das semelhanças e a ordem quantitativa das equivalências. Os ciclos e as igualdades são seus símbolos. Mas, de toda maneira, a generalidade exprime um ponto de vista segundo o qual um termo pode ser trocado por outro, substituído por outro. A troca ou a substituição dos particulares define nossa conduta em correspondência com a generalidade [...]. Nós, ao contrário, vemos bem que a repetição só é uma conduta necessária e fundada apenas em relação ao que não pode ser substituído. Como conduta e como ponto de vista, a repetição concerne a uma singularidade não trocável, insubstituível. (DELEUZE, 2000, p. 11)

A repetição está ligada à produção de singularidades e diferenças internas, portanto, nunca temos como resultado algo idêntico ao original. A repetição é considerada o "motor" da diferença, uma transgressão. Quando se repete algo, dirá Deleuze, surge algo único e singular, pois tempo, espaço e mudanças da natureza geram a impossibilidade da repetição idêntica. Quando Deleuze afirma que não há repetição sem um repetidor, demonstra a importância de considerar as singularidades naquilo que se repete, pois, além da ação repetida existe o ser que a repete. Deleuze põe a alma como objeto amoroso da repetição, e essa nunca pode ser repetida ou trocada. 


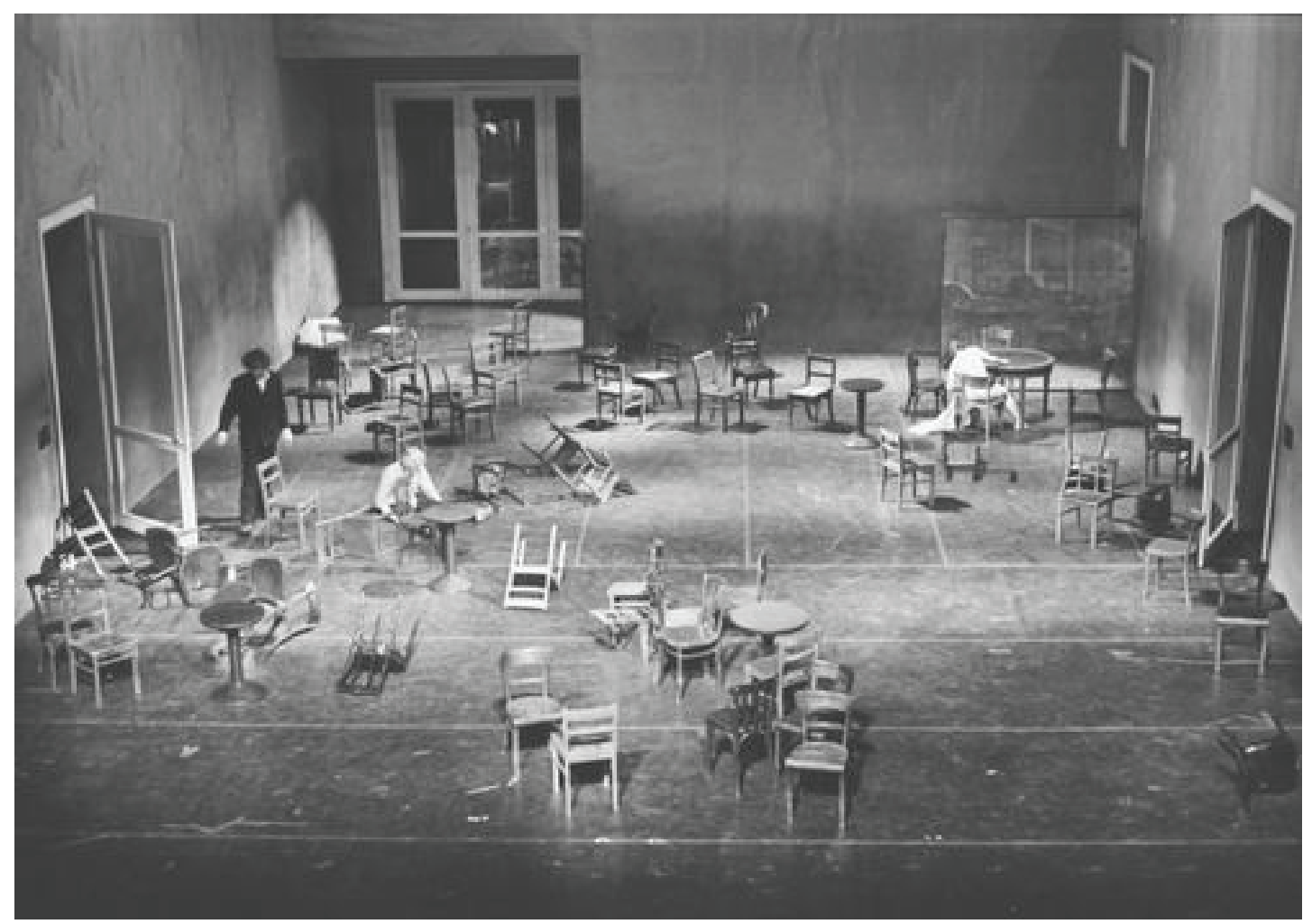

\section{Cenário do Espetáculo "Café Müller" de Pina Bausch}

Wuppertal, 1978. ${ }^{2}$

Nessa proposta de Bausch, com a incessante repetição em seus processos coreográficos, ao pedir que os bailarinos repitam diversas vezes o mesmo movimento, a ação é transformada porque ultrapassa um tempo, uma natureza e chega a mostrar a alma do bailarino. "O interior da repetição é sempre afetado por uma ordem de diferença." (DELEUZE,2000, p.33). A repetição não existe por dependência, pois para ela acontecer a ação anterior precisa desaparecer antes que a segunda aconteça, ou seja, ela é descontinua e instantânea. 
A repetição se apaga ao se multiplicar, provocando transformação. A presença evoca ausência, enquanto Ser torna-se simultaneamente Ser e não-Ser (eis de fato a questão) constantemente modificando no tempo e no espaço. (FERNANDES, 2007, p.139)

Para Deleuze, a repetição é concebida como uma forma pura do tempo, referindo-se ao futuro, não como uma reapresentação, mas como a condição de mudança do ser, do devir. A repetição é então transgressão e não generalidade. Toda ação tem uma parcela de individualidade que a difere de qualquer outra, mesmo que seja em seu interior. A repetição é tida como uma forma de subverter a lei, ela remete a uma potência da singularidade em cada ação.

Repetir é comportar-se, mas em relação a algo único ou singular, algo que não tem semeIhante ou equivalente. Como conduta externa, esta repetição talvez seja o eco de uma vibração mais secreta, de uma repetição interior e mais profunda no singular que a anima. A festa não tem outro paradoxo aparente: repetir um "irrecomeçável ". Não acrescentar uma segunda e uma terceira vez à primeira, mas elevar a primeira vez à "enésima" potência. (DELUZE, 2000, p,11)

"Elevar a primeira vez à 'enésima' potência" - era isso que Pina Bausch queria de seus bailarinos ao propor tantas repetições em seus processos. Ela não desejava que as ações fossem igualmente repetidas, mas que a cada vez que fossem executadas tivessem uma potência maior, fossem modificando, transformando, provocando uma diferença no repetidor e em quem assistia às ações.

(...) porque o bailarino (...) não fica a mesma pessoa que começou quando repete os movimentos (...) e ela gosta de ver essas mudanças com o mesmo tipo de movimento (...) [O] movimento (...) é carregado de possibilidades que, quando você vai repetindo tantas vezes, (...) vão crescendo e vão se adicionando. (Amarantes, apud, FERNANDES 2007, p. 51)

Quando um artista repete, ele não experimenta o mesmo diversas vezes, pois a cada experimentação surgem novas sensações, novas percepções, novas concepções. Deleuze fala de alma e também de coração, a cabeça para ele é o elemento das trocas que são feitas entre os iguais, mas o coração, a alma é o elemento da repetição. Não há possibilidade de trocar a alma de quem experimentou a repetição. A repetição Deleuziana é baseada na singularidade e na diferença interna, por isso se fala de alma e coração, por mais idêntica que a ação seja realizada no exterior, seu interior sofre com as singularidades do repetidor.

As repetições em Bausch são usadas como uma forma de repetir os afetos da vida transformados em frases de movimentos, uma repetição diária das mesmas ações, porém sempre 
diferentes. As repetições provocam aperfeiçoamento e interação, por isso não podem permanecer as mesmas, não se pode ter uma repetição idêntica, mesmo que seja uma ação realizada todos os dias.

A repetição é a potência da linguagem e do pensamento:

“É na repetição, é pela repetição que o Esquecimento se torna uma potência positiva e o inconsciente, um inconsciente superior positivo (por exemplo, o esquecimento, como força, faz parte integrante da experiência vivida do eterno retorno). Tudo se resume à potência. (DELEUZE, 2000, p.17)

Pensando no desejo de criação de Bausch de desvincular o gesto do seu cotidiano, talvez seja esse esquecimento provocado pela repetição que ela busca para potencializar as ações em cena. "O teatro é o movimento real e extrai o movimento real de todas as artes que utiliza. Eis o que nos é dito: este movimento, a essência e a interioridade do movimento, é a repetição, não a oposição, não a mediação." (DELEUZE, 2000, p. 19). A busca por essa interioridade de movimento é provocada tanto no bailarino que repete quanto no espectador que recebe a ação. $\mathrm{O}$ ato de repetir faz com que adentremos com nossa alma a ação realizada ou recebida. Para o filósofo, a repetição tece um ponto notável a outro, partindo das diferenças expostas em cada repetição ocorrida nos ensaios.

Quando, ao contrário, se diz que o movimento é a repetição e que é este nosso verdadeiro teatro, não se está falando do esforço do ator que "ensaia repetidas vezes" enquanto a peça ainda não está pronta. Pensa-se no espaço cênico, no vazio deste espaço, na maneira como ele é preenchido, determinado por signos e máscaras através dos quais o ator desempenha um papel que desempenha outros papéis; pensa-se como a repetição se tece de um ponto relevante a um outro, compreendendo em si as diferenças. (DELEUZE, 2000, p.19)

No teatro da repetição experimentam-se formas puras as quais agem sobre os espíritos que ligam diretamente à natureza; "experimentamos uma linguagem que fala antes das palavras, gestos que se elaboram antes dos corpos organizados, máscaras antes das faces, espectros e fantasmas antes dos personagens - todo o aparelho da repetição como "potência terrível". (DELEUZE, 2000, p. 19). Ao repetir uma sequência, tanto o repetidor quanto o espectador já esperam pelo próximo momento, é uma forma de existir antes da ação, é lembrar o que se viu no passado, diante do presente e prever o futuro. É uma forma de permear entre os três tempos. A repetição é então uma diferença sem conceito, ela tem uma potência na sua própria existência, ela existe na intuição. 
Quando falta a consciência do saber ou a elaboração da lembrança, o saber, tal como é em si, não vai além da repetição de seu objeto: ele é desempenhado, isto é, repetido, posto em ato, em vez de ser conhecido. A repetição aparece aqui como o inconsciente do livre conceito, do saber ou da lembrança, o inconsciente da representação. (DELEUZE, p.23)

Bausch utilizou muito a repetição para tornar vivas as memórias de seus bailarinos. Seu método de perguntas aproximava seus bailarinos das obras, era uma busca por memórias vividas, por verdades que fossem compatíveis com o tema da obra. As respostas dadas em movimentos eram repetidas, repetidas, repetidas, até adentrarem esse inconsciente da repetição e se tornarem novas a cada execução.

"A repetição é uma condição da ação antes de ser um conceito da reflexão. Só produzimos alguma coisa de novo com a condição de repetir uma vez do modo que constitui o passado e outra vez no presente da metamorfose" (DELEUZE, 2000, p.95). A metamorfose do movimento, é o que Bausch queria expor ao propor a seus bailarinos que repetissem várias vezes o mesmo movimento em cena. Em seu relato, Ruth Amarantes, bailarina de Bausch (FERNANDES, 2007), diz que ver a mudança do corpo e suas reações diante da mesma ação é o que instigava o trabalho da encenadora, ela gostava e expunha essas mudanças em cena. Bausch não só utilizava essas alterações como processo coreográfico, como expunha esse caminho à exaustão do bailarino em cena. Ela utilizava a repetição além do processo de pesquisa corporal, ela a colocava em cena, causando uma fadiga também no espectador que presenciava aquela incessante repetição de movimento.

\section{Repetição enquanto diferença}

As repetições em suas obras eram utilizadas em vários momentos e de diversas formas. A mesma frase repetida várias vezes em sequência em outro momento da mesma cena; só um fragmento da frase em outra cena; em todas essas opções ela ressaltava a diferença da repetição, que nunca se faz idêntica em nenhum dos momentos acima citados.

O artista combina um elemento de um exemplar com um elemento de outro exemplar, num processo dinâmico de construção provocando desequilíbrio e instabilidade que só terá sentido num conjunto total (DELEUZE, 2000). Bausch explorou os gestos repetidos ${ }^{3}$ em momentos e em relações diferentes; essas combinações provocam até inversão nos sentidos dos mesmos gestos. "A repetição do mesmo movimento traz mais e mais distorções, provocando múltiplas e imprescindíveis interpretações e experiências". (FERNANDES, 2007, p.127). 
Num dado momento, Deleuze (2000) fala de duas espécies de repetição: uma estática e a outra dinâmica.

O primeiro tipo é uma repetição estática, o segundo é uma repetição dinâmica. O primeiro resulta da obra, mas o segundo é como a "evolução" do gesto. O primeiro remete a um mesmo conceito, que deixa subsistir apenas uma diferença exterior entre os exemplares ordinários de uma figura; o segundo é repetição de uma diferença interna que ele compreende em cada um de seus momentos e que ele transporta de um ponto relevante a outro. Pode-se tentar assimilar estas repetições dizendo-se que, do primeiro ao segundo tipo, é somente o conteúdo do conceito que muda, ou dizendo-se que a figura se articula distintamente. Mas isto seria desconhecer a ordem respectiva de cada repetição, pois, na ordem dinâmica, já não há conceito representativo nem figura representada num espaço preexistente. Há uma Idéia e um puro dinamismo criador de espaço correspondente. (DELEUZE, 2000, p.29)

A repetição dinâmica acontece de formas diferentes, mas não deixa de se repetir. O filósofo exemplifica com as aulas de natação, nas quais o aluno aprende na areia e depois deve repetir os movimentos no mar. Não é o mesmo, mas um movimento compreende o outro.

Segundo Deleuze (2000), a repetição é simbólica na sua essência e a diferença só é percebida na repetição. Ela desfaz à medida que se faz, por isso não é possível falar de segunda ou terceira vez se estamos tratamos do mesmo. A repetição é independência, descontinuidade, instantaneidade. A diferença habita na repetição.

A repetição nem é a permanência do Uno nem a semelhança do múltiplo. O sujeito do eterno retorno não é o mesmo, mas o diferente, nem é o semelhante, mas o dissimilar, nem é o Uno, mas o múltiplo, nem é a necessidade, mas o acaso. Ainda mais: a repetição no eterno retorno implica a destruição de todas as formas que impedem seu funcionamento, categorias da representação encarnadas no caráter prévio do Mesmo, do Uno, do Idêntico e do igual. (DELEUZE, 2000, p. 126)

A diferença não se dá entre a ação original e a cópia, mas entre duas ações, não existe uma hierarquia. Tudo muda na natureza, tudo dá lugar à sua repetição. Assim a repetição tratada por Deleuze, que dialoga com as obras de Bausch, é a repetição ligada às singularidades, a repetição que provoca transformação, diferença, é devir. Cada ação gerada é diferente, única, embora tenha nascido do mesmo esquema da anterior. Para eles, a repetição é produção e criação.

A principal ideia da repetição tanto num processo de criação quanto numa obra é provocar 
experiências inesperadas nos dançarinos e no público. Durante o processo de criação, a repetição leva o performer a um estado corporal no qual ele já não responde mais pelo seu corpo da mesma forma que respondia na primeira execução do movimento, fazendo com que o próprio corpo busque novas formas de se mover na nova condição física a que a repetição o levou. Já em cena, a repetição provoca o espectador, que já espera pelo próximo movimento, que pode acontecer ou não, que pode ser repetido num contexto totalmente diferente do que o espectador imagina, fazendo com que ele perceba a semelhança na diferença.

Bausch utiliza a repetição pensando também no aprimoramento técnico de seus bailarinos. É importante lembrar que, mesmo trabalhando com dança contemporânea na junção da dança e do teatro, suas apresentações eram altamente técnicas, ela não rejeitava a grandiosidade dessas artes.

Bausch utilizou a repetição para criar novos conceitos coreográficos e uma estética cênica, criticando o conceito antigo ${ }^{4}$.

Ciane Fernandes (2007) relata uma cena da obra Bandoneon (1980): um bailarino tenta repetidas vezes realizar um passo de balé, mas não consegue e cai ao chão várias vezes.

"Pela repetição, a falha tornou-se parte da sequência tanto quanto a tentativa. É como se ele estivesse, antes de tudo, contando uma estória sobre poder falhar tanto quanto acertar: ambas opções de dança (...)

A cena de Mercy rompe a convenção de que o aprendizado por repetição leva à perfeição, ligando ao contrário, o método ao erro. Ele repete porque errou, para fazer melhor da próxima vez, mas erra mais e mais." (FERNANDES, 2007, p. 81)

Aqui se percebe que a repetição levava ao erro e não ao aprimoramento de um gesto, o bailarino repete para errar, a repetição pode levar ao erro e não só a acertos.

Bausch, em consonância com a teoria de Deleuze, utiliza a repetição para provocar mudanças nos gestos cotidianos. Esses são repetidos em seus processos coreográficos até se tornarem estéticos. A repetição nas suas obras, jamais pode ser lida sobre o conceito de repetição idêntica, os movimentos sempre são diferentes uns dos outros quando são repetidos. Os significados vão se dissolvendo e sofrendo mutações em meio às repetições.

A repetição em Dança-Teatro é uma forma de conscientizar o corpo da própria história enquanto tópico simbólico e social em construção e transformação. "As repetições provocam 
mudanças nos eventos ou sequências, insistindo na constante perda da dança dentro de sua natureza performática, ao invés de tentar preservá-la. (FERNANDES, 2007, p.37). Nas obras de Bausch a repetição de movimentos e palavras multiplica seus significados, causando assim suas transformações.

Fernandes (2007) analisa partes de obras de Bausch e organiza as variações de repetições nas seguintes categorias: repetições formais e repetições implícitas.

As repetições formais incluem: A exata repetição de uma frase de movimento ("Obsessiva"); a repetição de uma cena com sutis diferenças ("Alterada"); a repetição do mesmo evento em contextos diferentes ("Intermitente"); a repetição de eventos previamente separados, agora simultaneamente na mesma cena ("Longo Alcance").

As repetições implícitas no processo criativo incluem: A reconstrução cênica de experiências passadas dos dançarinos, principalmente da infância e a reconstrução de um conto tradicional ou ópera. (FERNANDES, 2007, p.44)

\section{Conclusão}

Para Bausch, o importante era a vida e suas mudanças. Acredita que na repetição cotidiana tudo pode mudar de repente. Bausch utiliza a máxima "a repetição é a mãe do aprendizado" para inverter seus efeitos, promovendo novas maneiras de perceber e expressar, criticando as relações de poder entre corpo e sociedade.

Segundo Fernandes (2007), no processo criativo de Bausch a repetição é usada para desarranjar as construções gestuais da técnica ou da própria sociedade. É um método criativo no qual os bailarinos fragmentam suas experiências, reconstruindo, desestabilizando e transformando suas próprias histórias. A repetição também é parte estrutural do processo criativo, primeiro atua na reconstrução estética das experiências dos dançarinos; em seguida, as cenas são gradativamente moldadas em uma forma estética. As cenas repetitivas geram múltiplos significados. Bausch se apropria da repetição e a utiliza como estética coreográfica. A encenadora se aproveita da impossibilidade de repetição para criar novas possibilidades cênicas, pois, para a coreógrafa, essa impossibilidade de repetir sempre foi vista como novas possibilidades de criação.

Fernandes (2007) afirma que repetir é uma tentativa malsucedida de preservar o momento presente, uma vez que o gesto atual parece com o anterior mas é outro. "Através da repetição, 
a dança articula sua inerente qualidade efêmera" (FERNANDES,2007, p. 63). Por isso o velho conceito de repetição já não se aplica mais. A repetição é uma forma de levar tanto os dançarinos quanto o público à exaustão. Quando se cansam, inconscientemente seus corpos relaxam e se tornam menos críticos e mais receptivos, provocando neles novas experiências: "a repetição abre novas e inesperadas formas de perceber a vida humana no palco e no cotidiano." (FERNANDES, 2007, p. 75)

A encenadora adota a repetição para provocar um jogo simbólico e é nesse jogo que ela consegue transformar cada movimento a cada repetição. Os eventos não encontram um ponto único, mas disseminam-se mais e mais. Segundo Fernandes (2007), os dançarinos repetem os gestos para serem entendidos e o público ao assistir a representação cria novos significados.

A repetição evoca um significado reflexivo sobre sua estrutura inerentemente oca e paradoxal. Ao conceber sua falta de significado como significado, a repetição se contradiz e se reafirma, antes de tudo, como a forma estrutural do mutável, do que não aceita conteúdos ou formas finais e definitivas. (FERNANDES, 2007, p.111)

Assim a repetição para Bausch e Deleuze é transformação, é apropriação e alteração do outro.

Artigo recebido em julho de 2016 e aprovado em agosto de 2016.

\section{Notas}

1 Pina Bausch. Café Müller: disponível em http://www.youtube.com/watch?v=VCQ29EUwvrl. Acessado em 25 de outubro de 2014. 2 Imagem 1: Cenário do Espetáculo “Café Müller". Wuppertal, 1978. Do site: http://www.pinterest.com/pin/361554676305887738/ Nessa imagem que mostra o cenário de Café Müller, percebe-se a multiplicação do mesmo objeto.

3 "Café Müller," "Sagração da Primavera", "Bandoneon", são alguns exemplos de obras da encenadora, em que muito se explorou a repetição.

$4 \mathrm{O}$ conceito aqui criticado é o da repetição vista como algo que se multiplica da mesma forma, igual, sem nenhuma alteração. Algo que se multiplica idêntico a um modelo previamente estabelecido.

\section{Referências}

TRAVI, Maria Tereza Furtado. A dança da mente: Pina Bausch e psicanálise. Porto Alegre: EDIPUCRS, 2011.

FERNANDES, Ciane. Pina Bausch e o Wuppertal dança-teatro: repetição e transformação. São Paulo: Annablume Editora, 2007.

DELEUZE, Gilles. Diferença e Repetição. Lisboa: Relógio d'Água, 2000. 